Publisher: ELSEVIER SCIENCE BV, PO BOX 211, 1000 AE AMSTERDAM, NETHERLANDS

Subject Category: Food Chemistry, Food Science

DOI: 10.1016/s1466-8564(02)00029-2

http://www.sciencedirect.com/science/article/B6W6D-460DCD82/2/6635d1d53d56e6292a7878f14f1f7fdf

\title{
FLOW INJECTION DETERMINATION OF TOTAL CATECHINS AND PROCYANIDINS IN WHITE AND RED WINES
}

\author{
J. González-Rodríguez ${ }^{1}$, P. Pérez-Juan ${ }^{1}$ and M.D. Luque de Castroo ${ }^{2 *}$ \\ 1 R\&D Department Pérez Barquero, S.A. Avda. de Andalucía, 27, E-14550, \\ Montilla, Córdoba, Spain. Fax: 957 650208, E-mail: barquero@fiab.es \\ ${ }^{2}$ Analytical Chemistry Division, Campus of Rabanales. Annex C-3 Córdoba. Spain. \\ Fax: 34-957-218615, E-mail: qa1lucam@uco.es
}

An easily automatable flow-injection (FI) method for the determination of total catechins is reported. The method is based on the reaction of vanillin in acid medium to yield a coloured product with maximum absorption at $500 \mathrm{~nm}$. After optimisation by the univariate and multivariate approaches as required, the linear range was established (between 10 and $90 \mathrm{mgL}^{-1}$ and 10 and $250 \mathrm{mgL}^{-1}$ for white and red wines, respectively). Then, the assessment of the proposed versus the reference method was studied in terms of repeatability $\left(2.57 \mathrm{mgL}^{-1}\right)$, reproducibility (3.56 $\mathrm{mgL}^{-1}$ ) (no significant differences were found), detection and quantification limits (not far from those of the reference method and always sufficient for the determination of catechins in any type of wine), traceability (excellent correlation under all conditions) and sample throughput (23 samples $\mathrm{h}^{-1}$ for the proposed method versus 3 samples $\mathrm{h}^{-1}$ for the reference method). 


\section{Introduction}

Grapes contain non-flavonoid compounds in the pulp while flavonoid compounds are essentially located in the seeds and skin. An in-depth knowledge of the structures of the latter is of interest to explain their role in the evolution of wine during the vinification and aging processes. The main 3-flavonoid monomers in grape are $(+)$ catechin and its isomer (-) epicatechin. The former (Fig. 1a) has two benzene cycles bound by a saturated oxygen heterocycle. This structure contains two asymmetrical carbons $\left(C_{2}\right.$ and $\left.C_{3}\right)$ that gave rise to four isomers. Catechins may not be considered as tannins, as their molecular weight is too low [290.3 for $(+)$ catechin] and they have very restricted properties as compared with tannins, which have molecular weights ranging from 600 to 3500 . The molecular weight of catechins in their dimer form is high enough for binding to proteins. Catechins degradation in synthetic wine containing tartaric acid and iron traces yields dimers in which the two catechin units (the simplest procyanidin) are bound by an ethane group (Fig. 1b). These dimers are colourless, but they undergo a fast evolution to yellow forms with higher absorption than the products formed by either enzymatic oxidation or catechin autooxidation (Flanzy, 2000). This mechanism seems to play an important role in the non-enzymatic browning of white wines, which is directly corre- lated with flavanoid contents (Flanzy, 2000).<smiles>Oc1cc(O)c2c(c1)O[C@H](c1cc(O)c(O)c(O)c1)[C@H](O)C2</smiles><smiles>O=C(O)c1c(O)cc(O)c2c1OC(c1ccc(O)c(O)c1)C(O)C2</smiles>

Figure 1. (a) Catechin estructure. (b) Catechin dimer involving an ethane bound.

There are two common methods for determining catechin contents in wines. The first method, proposed in 1959 by Swain and Hillis for the catechin assays in wines and also applied to vinegars 
(García-Parrilla, Heredia, Troncoso \& González, 1997), is based on chemical derivatisation using vanillin to yield a quinoid product whose colour ranges from pale to intense pink-red with an absorption maximum at $500 \mathrm{~nm}$. The second method is based on HPLC with different detectors to obtain levels of individual catechins and procyanidins compounds (Carando, Teissedre, Pascual-Martínez \& Cabanis, 1999). Capillary electrophoresis is also being used at present (Prasongsidh \& Skurray, 1998). There are no references in the literature on flow injection methods for the determination of catechins.

The objective of this work was to develop a flow injection method for determining catechins in their usual range of concentrations in MontillaMoriles white wines (Sherry type) (15$35 \mathrm{mgL}^{-1}$ ) (Fabios, López-Toledano, Mayen, Mérida \& Medina, 2000) and red wines (10-100 $\mathrm{mgL}^{-1}$ ) (Mayen, Mérida \& Medina, 1995), showing a precision as required for wineries and faster than the methods used at present.

\section{Experimental}

\section{Apparatus and instruments}

The manifold used is outlined in Fig.2. It was built using a four-channel Gilson Minipuls-3 peristaltic pump (Villiers le Bel, France) fitted with a rate selector, two Rheodyne 5041 injection valves (one of them acting as selection valve) (Elkay, Galway, Ireland), and PTFE tubing of $0.5 \mathrm{~mm}$ i.d. (Scharlau, Barcelona, Spain). A PU 8625 spectrophotometer (Cambridge, UK) equipped with a Hellma 138-QS flow-cell (Hellma, Jamaica, NY) and connected to a Knauer recorder were also used. Statistical treatments were made using Statgraphics ${ }^{\mathrm{TM}}$ plus for windows 2.1.

\section{Reagents and solutions}

For both the reference and proposed method, a $0.25 \mathrm{gL}^{-1}$ catechin solution (purity 98\%) from Merck (Darmstadt, Germany) in ethanol, 37\% hydrochloric acid, 1 and 2,5\% vanillin solutions (puity> 99\%), respectively, and absolute ethanol from Panreac (Barcelona, Spain) were used.

Bidistilled water of high purity obtained from a Millipore Milli-Q plus system (Bedford, MA, USA), was used.

\section{Reference procedure}

Determination of catechin (Swain and Hillis method). A $0.25 \mathrm{gL}^{-1}$ catechin standard solution was prepared. $0,1,2$, 3, 5 and $10 \mathrm{~mL}$ of standard solution, 10 $\mathrm{mL}$ of $37 \%$ hydrochloric acid and $5 \mathrm{~mL}$ of $1 \%$ ethanol solution of vanillin were mixed in 25-mL flasks. After $20 \mathrm{~min}$ the absorbance at $500 \mathrm{~nm}$ was measured in cuvettes of $10-\mathrm{mm}$ pathlength. Ten milliliters of white wine and aliquots of $10 \mathrm{~mL}$ of 1:10 diluted red wine were poured instead of the standard solutions and the procedure was applied as described before. Blank samples contained all reagents but vanillin.

\section{Proposed method}

Figure 2 shows the manifold used for catechins determination. The sample without dilution was introduced into the 
loop of the injection valve (IV) and injected into an $18 \% \mathrm{HCl}$ aqueous solution which merged with solution 1 (2.5\% vanillin in $35 \% \mathrm{HCl}$ ).

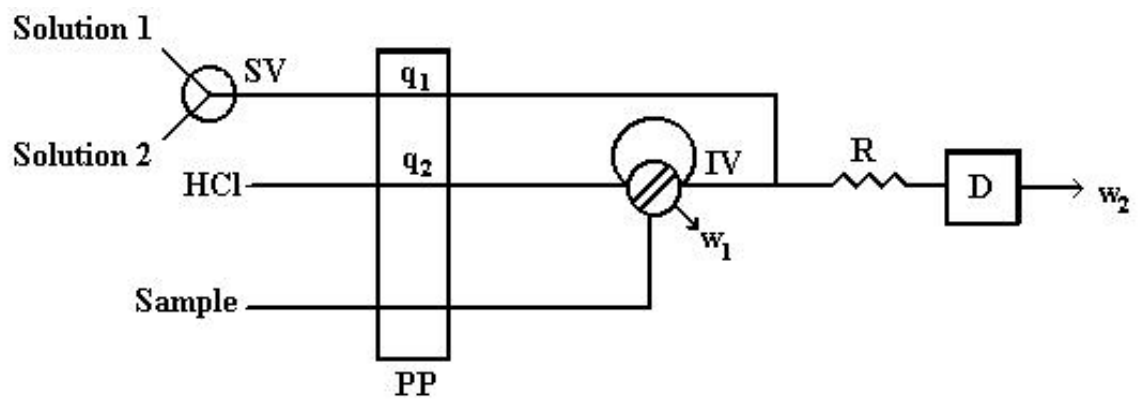

Figure 2. Manifold for the determination of catechins. $\mathrm{PP}=$ peristaltic pump, $\mathrm{q}=$ flow-rate, $\mathrm{SV}=$ selection valve, $\mathrm{IV}=$ injection valve, $\mathrm{R}=$ reactor, $\mathrm{D}=$ detector, $\mathrm{w}=$ waste.

The pink product of the derivatisation reaction was monitored at 500 $\mathrm{nm}$. After this, the selection valve (SV) was switched to the position for introducing solution $2(35 \% \mathrm{HCl})$ and a new sample aliquot was injected. The difference of absorbance between the two measurements at $500 \mathrm{~nm}$ was related to the catechins and procyanidin contents.

\section{Results and discussion}

\section{Optimisation of the method}

The variables which affect the method for the determination of catechins were studied by univariate and multivariate approaches depending on their interdependence and the optimum values obtained are summarised in Table 1.

\section{Chemical variables}

Figure 3 shows a plot of the absorbance values versus both the hydrochloric acid and vanillin concentrations in solution 1. As the P-value in the
ANOVA table is less than 0.05 , there is a statistically significant relationship between the variables at 95\% confidence level. The R-squared statistic indicates that the model explains $98,87 \%$ of the absorbance variability. The equation of the fitted model is: $\mathrm{A}=0.0470-7.68 \times 10^{-3}[\mathrm{HCl}]$ +0.0228 [vanillin] $+3.36 \times 10^{-4}[\mathrm{HCl}]^{2}+$ $1.46 \times 10^{-3} \quad$ [HCl][vanillin] -0.071 [vanillin] ${ }^{2}$, where $\mathrm{A}$ is expressed in milli-absorbance units and the concentration of vanillin in $\%(\mathrm{~m} / \mathrm{v})$.

Table 1. Optimisation study of the variables affecting the FI method for total catechins and procyanidins

\begin{tabular}{lll}
\hline Variable & $\begin{array}{l}\text { Tested } \\
\text { range }\end{array}$ & $\begin{array}{l}\text { Optimum } \\
\text { value }\end{array}$ \\
\hline$\underline{\text { Chemical }}$ & & \\
\% HCl (v/v) & $0-37$ & 37 \\
$\%$ Vanillin (m/v) & $0.1-3$ & 2.5 \\
$\underline{F I}$ & & \\
$\mathrm{q}_{1}\left(\mathrm{mLmin}^{-1}\right)$ & $0.4-1.3$ & 0.7 \\
$\mathrm{q}_{2}\left(\mathrm{mLmin}^{-1}\right)$ & - & 0.4 \\
Sample volume $(\mu \mathrm{l})$ & $50-500$ & 100 \\
$\mathrm{R}(\mathrm{cm})$ & $50-175$ & 75 \\
\hline
\end{tabular}


The response surface shows that the most critical variable is the concentration of $\mathrm{HCl}$ which clearly affects the sensitivity of the determination. In order to increase the sensitivity, a 37\% $\mathrm{HCl}$ concentration was chosen for further experiments. The range of vanillin concentrations studied showed that there were small differences in the absorbance when concentrations higher than $0.5 \%$ were used. A value of $2.5 \%$ was chosen in order to increase the instrument response. The optimum concentration of $\mathrm{HCl}$ in the carrier stream was $18 \%(\mathrm{v} / \mathrm{v})$.

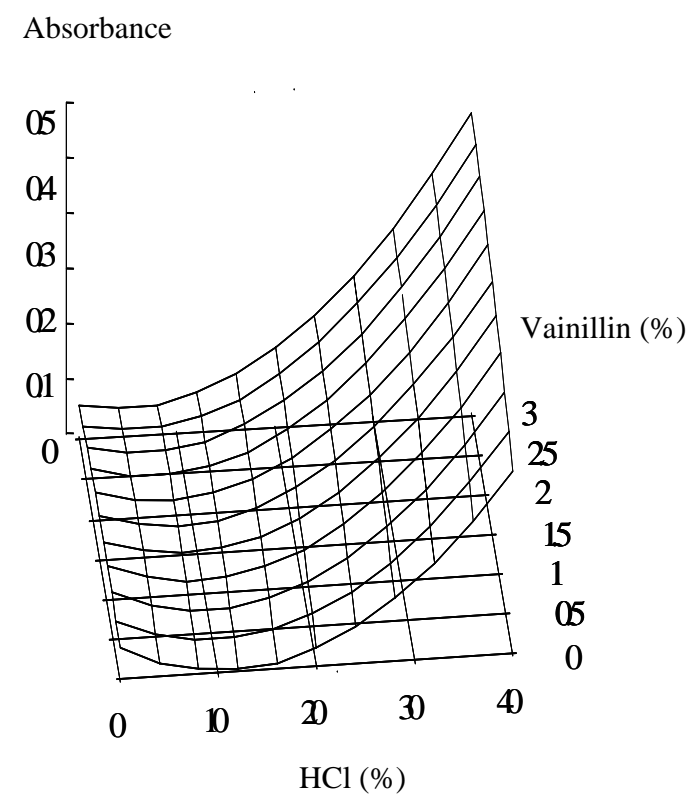

Figure 3. Response surface of the multivariate analysis: evolution of absorbance versus hycrochloric acid $(\%, \mathrm{v} / \mathrm{v})$ and vanillin concentration $(\%, \mathrm{~m} / \mathrm{v})$ in solution 1.

\section{Flow injection variables}

The function of reactor (indicated as $\mathrm{R}$ in Fig. 2) was to provide both appropriate reagent-sample mixture and enough development of the derivatisation reaction before reaching the detector. A length of $75 \mathrm{~cm}$ was sufficient for these purposes. The flowrate of the reagents was studied in the range $0.4-1.3 \mathrm{~mL} \mathrm{~min}^{-1}$ at constant

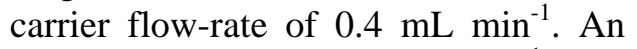

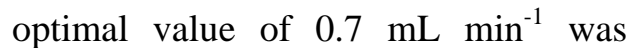
found for $\mathrm{q}_{1}$ (see Fig.2). A flow rate of $0.4 \mathrm{~mL} \mathrm{~min}{ }^{-1}$ was selected for the carrier channel $\left(\mathrm{q}_{2}\right)$ in order to minimise dispersion. The sample volume was tested from 50 to $500 \mu \mathrm{L}$ and no significant differences in the absorbance response were found above $100 \mu \mathrm{L}$.

\section{Characterisation of the method}

\section{Calibration curves}

Calibration curves were run using as standard solutions white and red wine samples spiked with known concentrations of catechin (between 10 and 40 $\mathrm{mg} \mathrm{L}^{-1}$ and between 10 and $250 \mathrm{mg} \mathrm{L}^{-1}$ for white and red wines, respectively) in order to minimise matrix effects. Each point in the curves was obtained as the average of a triplicate injection. Linear responses were found in the range of concentrations studied. In addition, standard solutions were analysed in triplicate by the reference method. 


\section{Assessment of the proposed method}

Thirty different white and red wines samples were used in the assessment study. Each result was the average of a triplicate injection. The protocol for assessment consisted of studying parameters such as traceability with a reference method, repeatability, reproducibility, detection and quantification limits and sample throughput. A robustness study was also developed.

Repeatability ( $r$ ). The F-test was applied in order to establish if the differences in repeatability of the methods was significant. With this aim, the Fobs $=\mathrm{S}_{\mathrm{r}}^{2} / \mathrm{S}_{\mathrm{ref}}{ }^{2}$ was compared with the $F_{1-\alpha}$ obtained from $F$ tables for $\alpha=0.05$ ( $P=95 \%)$. As can be observed in Table 2, Fobs $<\mathrm{F}_{1-\alpha}$, so the repeatabilities of the FI and reference method are similar. It is worth to noting that the repeatability of the flow injection method is better than that of the reference method.

Reproducibility (R) (30 days). Table 2 also shows the $R$ values obtained as well as the results from the application of the F-test. The reproducibility of the FI method is better than that of the reference method. Both methods are statistically equal.

Table 2. Analytical characteristics of proposed method and the reference method

\begin{tabular}{|c|c|c|}
\hline Parameters & $\begin{array}{l}\text { Reference } \\
\text { Method }\end{array}$ & $\begin{array}{c}\text { Flow injection } \\
\text { method }\end{array}$ \\
\hline Repeatability ( $\mathrm{mg} \mathrm{l}^{-1}$ ) & 3.10 & 2.57 \\
\hline $\mathrm{S}_{\underline{\underline{r}}}\left(\mathrm{mgL}^{-1}\right)$ & 0.56 & 0.45 \\
\hline Reproducibility (mg l${ }^{-1}$ ) & 5.30 & 3.56 \\
\hline $\mathrm{S}_{\underline{\mathrm{R}}}\left(\mathrm{mg} \mathrm{l}^{-1}\right)$ & 1.02 & 0.95 \\
\hline Fobs ${ }^{r}$ & - & 0.646 \\
\hline Fobs $^{\mathrm{R}}$ & - & 0.867 \\
\hline $\mathrm{F}_{1-\alpha}(\mathrm{n}=30)$ & - & 1.69 \\
\hline LOD $\left(\mathrm{mg} \mathrm{l}^{-1}\right)$ & 2.2 & 4.5 \\
\hline $\mathrm{LQ}\left(\mathrm{mg} \mathrm{l}^{-1}\right)$ & 6.1 & 5.85 \\
\hline Sample throughput $\left(\mathrm{h}^{-1}\right)$ & 3 & 23 \\
\hline
\end{tabular}

Where $\mathrm{S}_{\mathrm{r}}$ and $\mathrm{S}_{\mathrm{R}}$ are the deviation of repeatability and reproducibility, respectively. Fobs $=\mathrm{S}_{\mathrm{r}}{ }^{2} / \mathrm{S}_{\mathrm{ref}}{ }^{2}$

Detection (LOD) and quantification (LQ) limits. Table 2 shows that the best LOD and LQ correspond to the reference method but the values of these parameters in the FI method are not far from those of reference method.

Traceability. The traceability of the methods was studied by comparing the results obtained from 30 samples of red and white wines analysed by both the reference and proposed methods. Fig. 4 shows the regression of the flow injection method versus the reference method for catechins in both red wines (Fig. 4a) and white wines (Fig. 4b). The regression equations, (A) $y=0.998 \mathrm{x}+$ $0.462(r=0.993)$ and $(B) y=0.984 x+$ $0.451(r=0.993)$ show good correlation 
between data from both methods. Confidence limits of $95 \%$ are shown in the figure in dotted lines. In both cases the traceability was assured using the ttest.
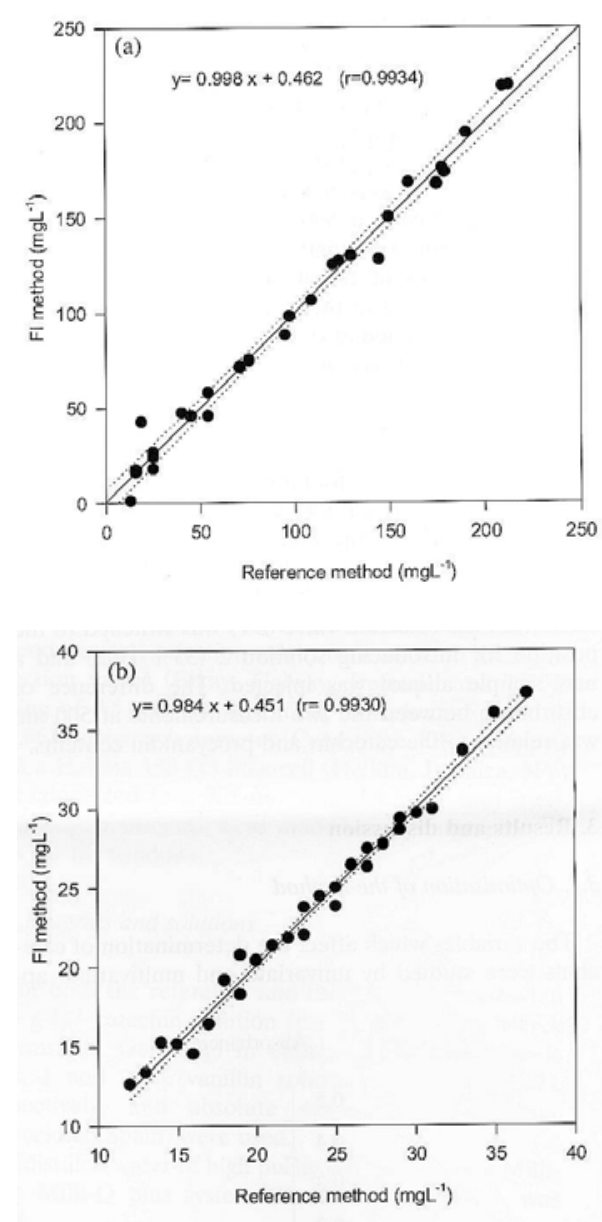

Figure 4. Correlation graphs of the reference method versus the FI method for the determination of catechins in: (A) red wine (B) white wine. Confidence interval: 95\%.
Sample throughput. The results in Table 2 show that the FI method provides a sampling frequency much higher than that of the reference method. This is a consequence of the non-equilibrium but fixed-time conditions in which FI measurements are performed. Thus, there is not necessity for waiting until reaction completion.

Robustness study. The study was developed using the Younden-Steiner procedure. Critical variables of the system are hydrochloric acid, vanillin concentrations in solution 1 and flowrate. These variables were modified $\pm 10 \%$ of their optimum values. All errors were below $5 \%$, except in the case of hydrochloric, which yields changes of $50 \%$ in the analytical signal in the range under study.

\section{Conclusions}

The proposed method enables the overall determination of catechins in red and white wine with characteristics similar or better than those of current existing methods. Thus, the proposed method is simple, inexpensive, presents a good correlation with the reference methods commonly used for these analytes and can be easily implemented in a winery for monitoring catechins in both white and red wines. Other advantages of the method are a sampling throughput higher than that of the methods routinely used in wineries and its capability for either partial or full automation.

This method constitutes the unique application of flow injection for the 
determination of catechins in white and red wines proposed so far and offers the advantage of reducing time and costs.

\section{Acknowledgement}

The Spanish Comisión Interministerial de Ciencia y Tecnología (CICyT) is thanked for financial support (Project BQU 2000/0241). The Agricultural Chemistry and Edafology Department of UCO is also thanked for technical and bibliographic support.

\section{References}

Carando S., Teissedre P.L., PascualMartínez L., Cabanis J.C. (1999). Levels of flavan-3-ols in French wines. J. Agric. Food Chem., 47, 4161-4166.

Fabios M., López-Toledano A., Mayen M., Mérida J., Medina M. (2000). Phenolic compounds and browning in Sherry wines subjected to oxidative and biological aging. J. Agric. Food Chem., 48, 2155-2159.

Flanzy, C. (2000). Enología: Fundamentos científicos y tecnológicos. AMV Ed. Mundi Prensa. Madrid, p.129.

García-Parrilla M.C., Heredia F.J., Troncoso A.M., González A.G. (1997). Spectrophotometric determination of total procyanidins in wine vinegars. Talanta, 44, 119-123.

Mayen M., Mérida J., Medina M. (1995). Changes in phenolic com- pounds and browning during biological aging of Sherry-type wine. Am. J. Enol. Vitic., 46, 256-261.

Prasongsidh B.C., Skurray G.R. (1998). Capillary electrophoresis analysis of trans- and cis-resveratrol, quercetin, catechin and gallic acid in wine. Food Chem., 62, 355-358. 